\title{
Extraction of Uranium from Artificial Liquid Waste using Continuous Flow Emulsion Liquid Membrane Technique
}

\author{
Rusdianasari ${ }^{1, *}$, Yohandri Bow ${ }^{2}$, Tresna Dewi ${ }^{3}$, and Eka Sri Yusmartini ${ }^{4}$ \\ ${ }^{1}$ Chemical Engineering Department, Renewable Energy Engineering, Politeknik Negeri Sriwijaya, \\ Palembang, Indonesia \\ ${ }^{2}$ Chemical Engineering Department, Energy Engineering, Politeknik Negeri Sriwijaya, Palembang, \\ Indonesia \\ ${ }^{3}$ Electrical Engineering Department, Politeknik Negeri Sriwijaya, Palembang, Indonesia \\ ${ }^{4}$ Chemical Engineering Department, Universitas Muhammadyah, Palembang, Indonesia
}

\begin{abstract}
The continuous extraction of uranium from artificial wastewater by an emulsion liquid membrane containing di-2ethylhexylphosphoric acid (D2EHPA) and tri-n-butyl phosphate (TBP) as the carrier was carried out using one stage mixer-settler. The optimum condition gave the ratio of emulsion velocity to the feed velocity $1: 4$ and steady state reached after five minutes. The optimum condition was obtained at the $90.91 \%$ of uranium recovered from raffinate, using EDTA as the masking agent with concentration $5 \times 10-2 \mathrm{M}$. The total concentration of carrier was 3\% with ratio D2EHPA and TBP 3:1. The emulsion liquid membrane has high relative selectivity after steady state with separation factors were $\mathrm{U}_{\mathrm{Ni}} 115.43$ and $\mathrm{U}_{\mathrm{Fe}} 328.55$. The result of the experiment showed that emulsion liquid membrane containing D2EHPA and TBP as the carrier have good performance for the continuous system.
\end{abstract}

\section{Introduction}

The separation, purification, and enrichment of chemical elements present in the mixture is an important issue faced by many chemical and nuclear industries in recent years. Likewise, ways of handling chemicals with high levels of impurities such as nuclear industry waste are a matter of urgency. For example in the handling of uranium waste which is one of several radionuclides commonly found in wastewater from processing facilities or use of nuclear material and active substances. To reduce the risk and not harm human beings and the environment requires proper management and segregation.

The liquid membrane is a liquid phase which separates (barrier) two other liquid phases that are not mixed with the membrane phase. The liquid membrane may consist of a hydrophobic liquid phase that divides the two liquid phases hydrophilic or hydrophilic phase which bisects the hydrophobic phase. The two liquid phases separated by liquid membrane each are called the external phase (feed / continuous) and the internal phase. The two liquid phases separated by liquid membrane each are called the external phase (feed /

\footnotetext{
*Corresponding author: rusdianasari@polsri.ac.id
} 
continuous) and the internal phase. The external phase contains a substance to be separated, while the internal phase is the receiving phase of the substance after passing through the liquid membrane $[1,3]$.

The separation process by emulsion liquid membrane technique has two important stages. The first stage is the formation of the emulsion and the second stage is the separation/extraction. The emulsion that had been made dispersed into the feed / external phase by stirring. Therefore the emulsion grains used should be stable and not cracked during the stirring process. To maintain the stability of the emulsion during the process, and then into the membrane (surfactants) that normally work to reduce tension between the droplets of dispersed phase and feed phase [4,6].

In the separation process, uranium metal ions react with the carrier substance (extractant) on the surface of the membrane phase interface and the feed phase, forming a metal complex dissolved in an organic phase. The complexing agent that has released uranium metal ions is moving back to the surface of the organic phase to form a complex with uranium metal ions. This process is continuous so that most of the metal ions move from the feed phase and enrichment in the feed phase [7,9].

The equipment used for the continuous extraction process are divided into two types, they are mixers and columns. Mixer-settler is a composition comprising of two tank units consisting of mixing units and mixed phase shelters used for continuous processing. The two phases of the emulsion phase and the feed phase are fed into the mixer unit, and after stirring, the mixture is passed to the settler unit $[10,11]$.

$$
\alpha_{U, N i}=\frac{X_{U(o)} / X_{N i(o)}}{X_{U(a q)} / X_{N i(a q)}}
$$

\section{Materials and Methods}

The materials used are uranyl nitrate hexahydrate, di-2-Ethylhexyl phosphate, tributyl phosphate, sorbitan monooleate (Span-80), kerosene, nitric acid, phosphoric acid, arsenazo III, nickel nitrate and iron nitrate. Substances used in this study have a quality p.a (pro analysis).

The equipments used are a set of Fisher Dyna-Mix stirrer, UV-Vis Spectrophotometer, $\mathrm{pH}$ meter, peristaltic pump, analytical balance, stopwatch and commonly used glassware.

\subsection{Optimization of Parameters on the Batch System}

In this study, D2EHPA and TBP were tested as a carrier for the recovery of uranium metal ions by continuous flow extraction. Parameters to be tested to obtain optimum conditions for making membranes in batch are listed in Table 1. 
Table 1. Optimization of parameters in the manufacture of the membranes

\begin{tabular}{|c|c|c|}
\hline No. & Parameter & Variation \\
\hline 1. & Surfactant concentration (Span-80) (\%) & $1,2,3,4,5,6$ \\
2. & Comparison of D2EHPA and TBP & $1: 0 ; 1: 1 ; 2: 1 ; 3: 1 ; 1: 0 ; 1: 2 ; 1: 3$ \\
3. & Total concentration of carrier (\%) & $1,2,3,4,5,6$ \\
4. & Time of emulsion preparation (min) & $2.5 ; 5.0 ; 7.5 ; 10.0 ; 12.5$ \\
5. & Stirring speed of emulsion preparation (rpm) & $2900,3300,3500,3900,4500,5000$ \\
6. & Comparison $\mathrm{V}_{\mathrm{Fi}}: \mathrm{V}_{\mathrm{Fo}}$ & $1: 1 ; 1: 2 ; 1: 3 ; 1: 4 ; 1: 5$ \\
7. & Receiver phase concentration(H3PO4) $(\mathrm{M})$ & $0.25 ; 0.50 ; 0.75 ; 1.00 ; 1.25 ; 1.50$ \\
8. & Residence time (min) & $0 ; 5 ; 10 ; 15 ; 20$ \\
9. & $\mathrm{HNO}_{3}$ concentration in feed phase $(\mathrm{M})$ & $0.25 ; 0.50 ; 0.75 ; 1.00 ; 1.25$ \\
10. & Concentrations of uranium solution $(\mathrm{ppm})$ & $50,100,150,200,250$ \\
11. & Comparison $\mathrm{V}_{\mathrm{Fe}}: \mathrm{V}_{\mathrm{Feks}}$ & $1: 4 ; 1: 5 ; 1: 6 ; 1: 7 ; 1: 8$ \\
12. & Extraction time (min) & $5 ; 7.5 ; 10 ; 12.5 ; 15 ; 17.520 ; 25$ \\
13 & Stirring speed of extraction $(\mathrm{rpm})$ & $400,500,550$ \\
\hline
\end{tabular}

After parameter optimization is obtained, the parameters are used to recover uranium metal ions with continuous flow emulsion liquid membrane.

\subsection{Equipment Design}

The laboratory scale mixer-settler extraction apparatus consists of a mixer tank with two buffles and a settler tank made of glass. The inner diameter of the tank is $7.0 \mathrm{~cm}$ and the height is $14.0 \mathrm{~cm}$. The agitating tank is connected to the feed phase and emulsion phase in which the emulsion and emulsion phases are flowed at a particular rate. Schematic equipment in figure 1.

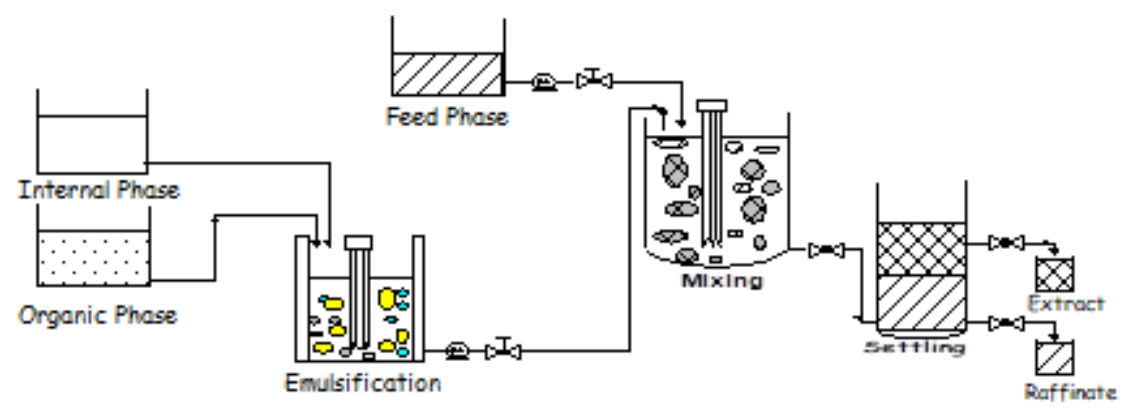

Fig. 1. Schematic of continuous extraction equipment

\subsection{Effect of Feed Flow Rate Flow}

The effect of changes in the feed phase flow rate is determined by varying the feed phase flow rate of $20 ; 24 ; 30 ; 60$; and $80 \mathrm{~mL} / \mathrm{min}$ and other parameters are fixed at the predetermined optimum value. 


\subsection{Determining Steady Time}

Steady time is the time the emulsion is dispersed in the feed phase so that the amount of uranium is extracted constant every time. For this determination the separations of the contact time variations as follows: 2, 4, 6, 8, 10, 12 minutes and other parameters are fixed at the predetermined optimum value.

\subsection{Uranium Extraction from Artificial Liquid Waste}

The artificial wastes are prepared with the following composition: uranium $100 \mathrm{ppm}, \mathrm{Ni}$ 410 ppm, and Fe 9392 ppm.5 This artificially prepared waste is used as the feed phase. The uranium concentration in the feed and raffinate phases was determined using a UV-Vis Spectrophotometer at a wavelength of $652 \mathrm{~nm}$ with a reactant forming the Arsenazo III complex, forming a blue complex. The calculation is done by using the calibration curve that has been made before. The concentrations of $\mathrm{Ni}$ and $\mathrm{Fe}$ in artificial and raffinate wastes were determined using AAS Shimadzu model AA 630-12. Ni is measured at $232 \mathrm{~nm}$ wavelength, and $\mathrm{Fe}$ is measured at $248.3 \mathrm{~nm}$ wavelength.

\section{Results And Discussions}

\subsection{Optimization of Parameters on the Batch System}

Optimization of parameters on the batch system taken at the extraction percentage reaches a minimum of $90 \%$ can be seen in Table 2 .

Table 2. Optimization of parameters for making membranes

\begin{tabular}{|c|c|c|}
\hline No. & Parameter & Optimization Results \\
\hline 1. & Surfactant concentration (Span-80) (\%) & 4 \\
2. & Ratio of D2EHPA and TBP & $3: 1$ \\
3. & Total concentration of substance carrier (\%) & 3 \\
4. & Time of emulsion making (min) & 5 \\
5. & Speed of stirring of emulsion making (rpm) & 3900 \\
6. & Ratio of $\mathrm{V}_{\mathrm{Fi}}: \mathrm{V}_{\mathrm{Fo}}$ & $1: 1$ \\
7. & Phase concentration of the receiver (H3PO4) (M) & 1 \\
8. & Residence Time (min) & 10 \\
9. & Concentration of $\mathrm{HNO}_{3}$ in the feed phase (M) & 0.5 \\
10. & Concentration of uranium solution (ppm) & 100 \\
11. & Ratio of $\mathrm{V}_{\mathrm{Fe}}: \mathrm{V}_{\mathrm{Feks}}$ & $1: 4$ \\
12. & Extraction time (min) & 5 \\
13. & Speed of extraction stirring (rpm) & 500 \\
\hline
\end{tabular}

The optimum parameter (optimum condition) was applied to continuous extraction.

\subsection{Effect of Speed of Feed Phase Flow}

The effect of speed of feed phase flow to uranium concentration (U(VI)) in raffinate was shown in Figure 2. The increase in the flow speed of the feed phase causes the decrease of $\mathrm{U}(\mathrm{VI})$ concentration in raffinate. A higher flow speed increase will not increase the excessive percentage of extraction, and this was presumably due to reduced time stay in the 
reactor so that $\mathrm{U}(\mathrm{VI})$ in the solution cannot be in contact with the emulsion maximally and the emulsion load was increasing so that its ability become reduced.

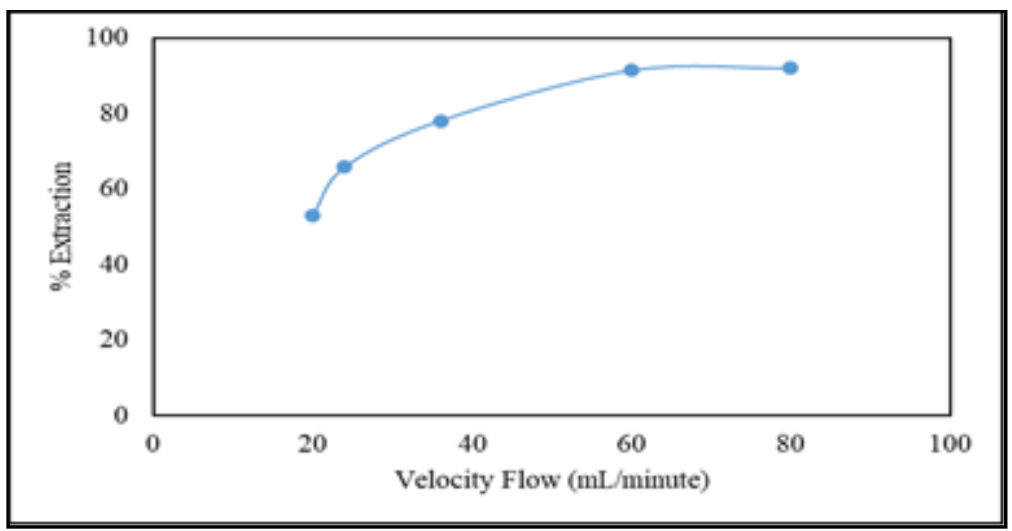

Fig. 2. Effect of Speed of Feed Phase Flow

\subsection{Determination of Steady Time}

The operation of a continuous process was done in a state of steady. The steady-state stated that shows the composition (concentration) U (VI) in raffinate constant to time. The state of steady was observed by measuring the concentrations of raffinate that exit every time interval certain.

In this experiment had observed steady time on the ratio of speed emulsion phase flow to feed of 1: 4. Figure 3 shows the state of separation process stages achieved after a 5 minute walk time. The state of steady is affected by the concentration of U (VI) in the feed phase because at different concentrations (up) the load of the liquid membrane to transfer $U$ (VI) to the receiving phase will increase. The state of steady was obtained at a concentration of U (VI) 100 ppm.

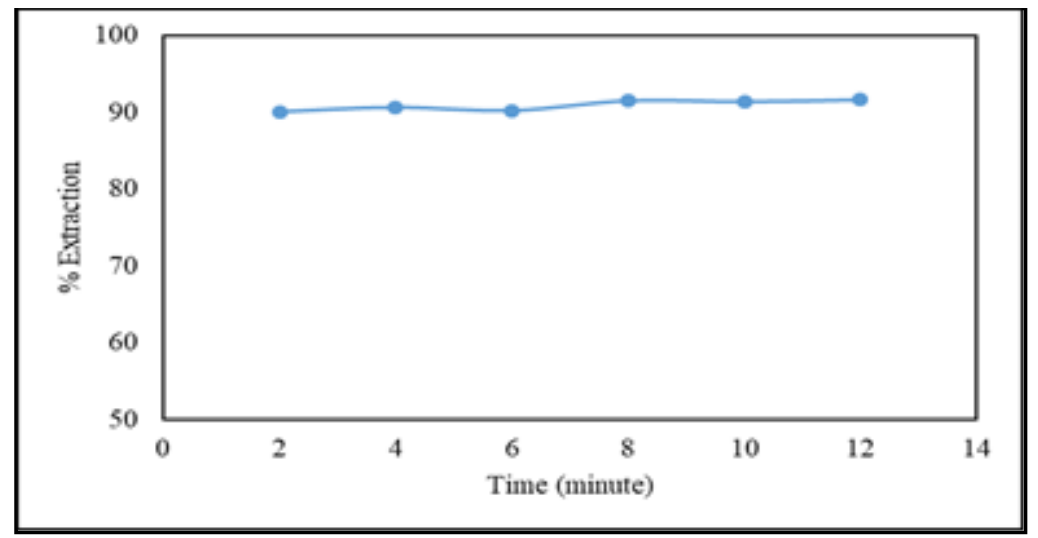

Fig. 3. Chart of SteadyTime 


\subsection{Separation of Uranium from Artificial Waste}

The result of the separation of $U$ (VI) from artificial liquid waste was measured by raffinate that had been separated from the emulsion phase. The results of the separation were shown in Figure. 3. From the figure, it was shown that U (VI) could be separated well from the 5th-minute percent of U (VI) extraction had reached above $85 \%$.

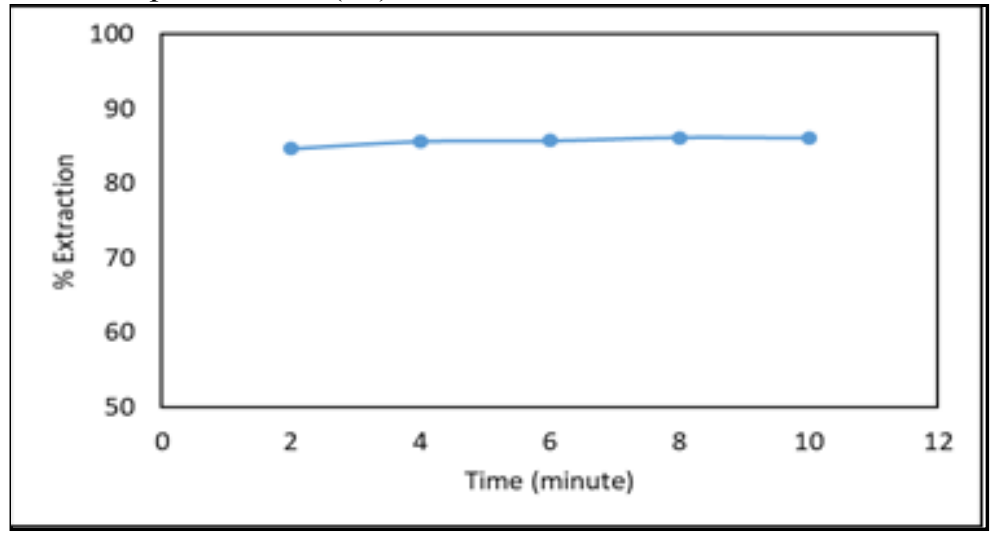

Fig. 4. Graph of separation U (VI) from artificial waste

The results of the separation through raffinate measurements gave an average percent extraction rate of $90.91 \%$ after steady time.

\subsection{Separation Factors}

The separation of the three ions depends on the effectiveness of the complex forming on the outer surface of the membrane/phase membrane and the difference in the rate of diffusion of the two complexes within the membrane. It was suspected that the formation of U (VI) complexes with carrier substances was more effective than other metal ions so that U (IV) could be transported more rapidly.

Despite the transport of $\mathrm{Ni}$ (II) and Fe (III) ions from the feed phase through the membrane phase, the relative transport did not affect the U (VI) extraction process in the waste. When viewed from the separation factor, the combined carrier might separate U (VI) by $>1$. The mean separation factor price obtained after the steady time on the artificial waste was $\mathrm{U}, \mathrm{Ni}=115.43$ and $\mathrm{U}, \mathrm{Fe}=328.55$.

\section{Conclusion}

The extraction continuous U (VI) from artificial waste with the emulsion liquid membrane can be carried out in the mixer-settler. It had been found that speed the ratio of the feed phase flow and emulsion phase was 4: 1, where speed the feed phase flow rate was $60 \mathrm{~mL} / \mathrm{min}$ and speed the emulsion phase flow is $15 \mathrm{~mL} / \mathrm{min}$, the steady time reached by the fifth minute of raffinate release..

Measurement of the separation results through raffinate provided extraction percent of 90.91\%. This indicates that the continuous flow of fluid emulsion membrane with substances of D2EHPA and TBP combined carrier had a good performance. The substances 
combined carrier D2EHPA and TBP had relatively good selectivity with the average separation factor values obtained after the steady time on the waste is $\mathrm{U}, \mathrm{Ni}=115.43$ dan $\mathrm{U}, \mathrm{Fe}=328.55$.

\section{References}

1. Saarangi, K., Indusekhar, V.K...Journal Research and Industry 52 (1993)

2. Bartsch, R.A., WAY, J.D. American Chemical Society. America (1996)

3. Hayworth, H.C., Burn, W.A. Journal Separation Science and Technology. 18, 6 (1983)

4. Danesi D.R., Chriarizia. J. Solvent Extraction and Ion Exchange. 3, 162 (1985)

5. Babcock WC, Friesen DT, Lachapelle ED. J Membr Sci. 26, 3 (1986)

6. Reed DL, Bunge AL, Noble RD. In: Noble RD, Way JD (eds) Liquid membranes: theory and applications. (American Chemical Society, Washington, DC, 1987)

7. Rusdianasari, Y. Bow, A. Taqwa. Advanced Materials Research. 896, 145-148 (2013)

8. R. Rusdianasari, A. Meidinariasty, I. Purnamasari. Int. J. on Adv. Sci. Eng. and Information Tech. 5, 6 (2015)

9. Y. Bow, H. Hairul, and I. Hajar. Int. J. on Adv. Sci. Eng. and Inf. Tech 5, 6 (2015)

10. Othman N, Mat H, Goto M. J Membr Sci 282 (2006)

11. SannaBjorkergen, Rose Fassihi Karim, Anna Martinelli, Natesan Subramanian and Mohd. Ali Hashim. J. Membranes. 5, 2 (2015). 